\title{
The Serendipity Theorem for an Endogenous Open Economy Growth Model
}

\author{
Thomas Ziesemer \\ Department of Economics and UNU-MERIT, Maastricht University, Maastricht, The Netherlands \\ Email: T.Ziesemer@maastrichtuniversity.nl
}

How to cite this paper: Ziesemer, T. (2018) The Serendipity Theorem for an Endogenous Open Economy Growth Model. Theoretical Economics Letters, 8, 720-727. https://doi.org/10.4236/tel.2018.84049

Received: January 1, 2018

Accepted: March 5, 2018

Published: March 8, 2018

Copyright (C) 2018 by author and Scientific Research Publishing Inc. This work is licensed under the Creative Commons Attribution International License (CC BY 4.0).

http://creativecommons.org/licenses/by/4.0/

\begin{abstract}
A Samuelsonian serendipity theorem for an endogenous growth model is derived. The formula for optimal population growth rate deviates from those of the model with exogenous population growth rates in a third best endogenous growth model of the Lucas type with imperfect international capital movements and human capital externalities. Calibration shows that the effect of variation of the exogenous population growth rates on other variables and the deviation of population growth rates from its optimal value are small. The reason is that labour supply, interest rates and technical change are endogenous. There is not much of an incentive for population growth policy unless Frisch parameters change with ageing.
\end{abstract}

\section{Keywords}

Open Economy, Endogenous Growth, Human Capital, Serendipity Theorem, Ageing

\section{Introduction}

Samuelson [1] re-considered the golden rule of Diamond's [2] two-period version of the neoclassical growth model asking which of the values of population growth rates yields the highest welfare and found a first-order condition which he called the serendipity theorem. Deardorff [3] showed that second-order conditions do not hold when Cobb-Douglas functions are used. Michel, etc. [4] showed that second-order conditions are fulfilled if CES functions for utility and production have elasticity of substitution smaller than unity or else additional conditions may become necessary. Samuelson's [1] result was generalized by Abio [5], Jaeger [6], De la Croix, etc. [7], and Felder [8] in regard to endogenous fertility, exogenous and constant government debt, risky life time and medical 
expenditure. ${ }^{1}$ We extend the theorem to endogenous growth with endogenous labour supply, imperfect international capital movements and human capital externalities in a third-best extension of Lucas's [10] model with optimization over all future generations by Gaessler [11].

\section{The Model}

The maximization program for the consumers is

$$
\begin{aligned}
& \max _{c_{t}, e_{t}, L_{t}, B_{t+1}, K_{t+1}, h_{t+1}} \sum_{t=0}^{\infty} \beta^{t}\left(N_{t}\left(\frac{c_{t}^{1-\sigma}}{(1-\sigma)}-\xi \frac{\left(\frac{L_{t}}{N_{t}}\right)^{1+\vartheta}}{1+\vartheta}\right)\right. \\
& -\mu_{t}\left[N_{t} c_{t}+K_{t+1}-\left(1-\delta_{k}\right) K_{t}-\omega_{t}\left(1-e_{t}\right) h_{t} L_{t}-r_{k t} K_{t}\right. \\
& \left.\left.-B_{t+1}+\left(1+r\left(\frac{B_{t}}{Y_{t}}\right)\right) B_{t}\right]-\mu_{h t}\left[h_{t+1}-F e_{t}^{\gamma} h_{t}-\left(1-\delta_{h}\right) h_{t}\right]\right)
\end{aligned}
$$

The expression above shows the utility function of the entire population, $N_{t}$ where $0<\beta<1$ is the subjective discount factor, $\sigma>0$ is the intertemporal elasticity of substitution for per-capita consumption, $c_{t}, \vartheta$ is the Frisch parameter for the active part of the population or labour supply, $L_{b}$ expressed as a share of the population, $\xi>0$ is a parameter which measures the disutility of participation in the active population relative to the consumption part of utility. The households decide between spending their time in production $\left(1-e_{t}\right)$ for immediate output generation and education, $e_{t}$, to increase their productivity for later production. Income from labor with human capital $h_{t}$ is $\omega_{t}\left(1-e_{t}\right) h_{t} L_{t}$, the income from capital rent is $r_{k t} K_{t}$, and the debt from outside the economy's borders minus the interest and re-payment is, $B_{t+1}-\left(1+r\left(\frac{B_{t}}{Y_{t}}\right)\right) B_{t} \cdot r\left(\frac{B_{t}}{Y_{t}}\right)$ is the debt dependent interest rate. Spending on consumption is $N_{t} c_{t}$, and gross capital investment is $K_{t+1}-\left(1-\delta_{k}\right) K_{t}$.

Consumption is not differentiated in regard to age or (not) working. This is implicit in the assumption of equal consumption of all for a given point in time. By implication, we do not model pay-as-you-go pension systems with defined benefits or contributions [12] but instead forward looking savings and equal consumption, where the latter is a social equilibrium assumption similar to that in [13].

The economy is assumed to consist of output-producing firms and labor-and

${ }^{1}$ An interesting but only slightly related class of problems with endogenous population growth rates is discussed in [9]. The major differences are that in their paper population growth rates appear in the utility function, technical change is exogenous and a closed economy is considered. As our lists of literature are not overlapping we do not try to compare results. 
capital-supplying consumers. Output is formed by a Cobb-Douglas production function and is determined by physical capital, $K_{t}$, and efficient labour, $\left(1-e_{t}\right) h_{t} L_{t}$. A human capital externality is added as, $\bar{h}_{t}^{\epsilon}$, modelled after Lucas [10], to include the influence of the average skill level on the economy.

This forms the production function

$$
Y_{t}=A\left(K_{t}\right)^{1-\alpha}\left(\left(1-e_{t}\right) h_{t} L_{t}\right)^{\alpha} \bar{h}_{t}^{\epsilon}
$$

The demand for physical and human capital is determined in a firm which maximizes profits:

$$
\begin{gathered}
\max _{\left(1-e_{t}\right), K_{t}} \pi=A\left(K_{t}\right)^{1-\alpha}\left(\left(1-e_{t}\right) h_{t} L_{t}\right)^{\alpha} \bar{h}_{t}^{\epsilon}-\omega_{t}\left(1-e_{t}\right) h_{t} L_{t}-r_{k t} K_{t} \\
\omega_{t}=\frac{\alpha Y_{t}}{\left(1-e_{t}\right) h_{t} L_{t}} \\
r_{k t}=(1-\alpha) \frac{Y_{t}}{K_{t}}
\end{gathered}
$$

Equations ((2) and (3)) represent first-order conditions, equating marginal productivity of labor and capital to wages for efficient labour and rental rates.

In the utility maximization, given the initial value $N_{t}$ only the level of the population, $N_{t+1\rangle}$, appears. ${ }^{2}$ It has three effects. Higher $N_{t+1}$ leads to higher temporary utility $N_{t+1} u_{t+1}$; any given labour time $L_{t+1}$ is shared among more people; more people have to be fed with additional consumption $N_{t+1} c_{t+1} .{ }^{3}$ The first-order condition for $N_{t+1}$, given $N_{t}$ and using (6) is

$$
u_{t+1} \equiv \frac{c_{t+1}^{1-\sigma}}{1-\sigma}-\xi \frac{\left(\frac{L_{t+1}}{N_{t+1}}\right)^{1+\vartheta}}{1+\vartheta} \geq(\leq)-\xi L_{t+1}^{1+\vartheta} N_{t+1}^{-1-\vartheta}+c_{t+1}^{1-\sigma}
$$

This condition is similar to that of [7], Equation (6), to which [8] has added the impact of medical expenditures and we add the labour supply term on the right-hand side. Collecting terms and dropping time indices $t+1$ yields

$$
c^{1-\sigma}\left(\frac{1}{1-\sigma}-1\right)(>)=(<)\left(\frac{L}{N}\right)^{1+\vartheta}\left(\frac{\xi}{1+\vartheta}-\xi\right)
$$

(4') is a condition for the optimal population level. If $\sigma>(<) 1$,

$\frac{\xi}{1+\vartheta}-\xi=\xi \frac{-\vartheta}{1+\vartheta}<(>) 0$ is required and fulfilled for any positive Frisch parameter.

As the Hamiltonian of the households dynamic problems defined above is already maximized for given $N_{t+p}$ when we derive with respect to $N_{t+1}$ - analogous to indirect utility in [4], the envelop theorem applies and we only have to take the direct derivative with respect to $N$-terms and the second derivative with respect to $N$ should be negative. For this we need $\xi-(1+\vartheta) \xi<0$ and because of (4') also $\sigma>1$. For our iso-elastic utility case, production has unit substitution elasticities and labour supply should have a positive elasticity for $\xi>0$.

${ }^{2}$ Equations (1)-(3) do not have $N_{t+1}$ terms.

${ }^{3}$ The first and the last effect are very similar to that of an increased survival probability in [8]. 
Equation (4') will only be fulfilled for specific values of $N_{t+1}$ as $c$ and $L$ are already optimally chosen by the household; it ensures that the two parts of utility are well balanced and consumption or labour supply are never too high or too low. However, $N$ can adjust only slowly without migration and therefore temporarily this may perhaps hold only with inequality.

First-order conditions from household's utility maximization for consumption $c$ and labour $L$ can be derived to find, together with (2),

$$
c_{t}=\xi^{-1 / \sigma}\left(\frac{L_{t}}{N_{t}}\right)^{-\vartheta / \sigma}\left(\alpha \frac{Y_{t}}{L_{t}}\right)^{1 / \sigma}
$$

This can be compared to our serendipity condition (4') in order to find the difference with the market equilibrium after making exponents comparable to (4'):

$$
\begin{aligned}
c_{t}^{1-\sigma} & =\xi^{(\sigma-1) / \sigma}\left(\frac{L_{t}}{N_{t}}\right)^{-\vartheta(1-\sigma) / \sigma}\left(\alpha \frac{N}{L} \frac{Y}{N}\right)^{(1-\sigma) / \sigma} \\
& =\xi^{(\sigma-1) / \sigma}\left(\frac{L_{t}}{N_{t}}\right)^{(-\vartheta-1)(1-\sigma) / \sigma}\left(\alpha \frac{Y}{N}\right)^{(1-\sigma) / \sigma}
\end{aligned}
$$

The equality form of the serendipity condition (4') is

$$
c^{1-\sigma}=\left(\frac{L}{N}\right)^{1+\vartheta} \xi\left(\frac{-\vartheta}{1+\vartheta}\right)\left(\frac{1-\sigma}{\sigma}\right)
$$

Equating right-hand sides of (4") and (5') we get

$$
\left(\frac{L}{N}\right)^{\frac{\vartheta+1}{\sigma}} \xi\left(\frac{-\vartheta}{1+\vartheta}\right)\left(\frac{1-\sigma}{\sigma}\right)=\xi^{(\sigma-1) / \sigma}\left(\alpha \frac{Y}{N}\right)^{(1-\sigma) / \sigma}
$$

Other first-order conditions for the dynamic problem of the household are shown in [11]. Together with Equations (1)-(3) they form a system of 11 equations for eleven variables. Successive insertion leads to a reduced system for the values for education time $e$ and the debt-output ratio $b$ depending on the population growth rate. These then determine the consumption share $X(=N c / Y)$. All the values solving the model could be found without an assumption regarding the level of $N$ as is well known for Lucas type of models. Equation (4) has no impact on the solution of the model for those variables. An increase of $N$ will shift $L, Y, K, B$ and $C$ equi-proportionately. The model solution that compares to (6) in terms of growth rates is

$$
\frac{\left(1+g_{Y}\right)}{\left(1+g_{N}\right)}=\left(1+g_{h}\right)^{1+\frac{\epsilon}{\alpha}} \frac{\left(1+g_{L}\right)}{\left(1+g_{N}\right)}
$$

where $g_{h}$ is the endogenous growth rate of productivity $h$ and it is constant in the steady state, which has no transition as the model can jump to its solution for $e$, $b, r(b)$,$X , and all other variables. Whereas the model solution (7) links the$ growth rate ratios of $Y / N$ and $L / N$ linearly, in (6) comparable growth rates have exponents. 
The growth rate of $N$ can contribute to welfare by ensuring that the level and growth rates of $c$ and $L / N$ do not get too far apart. Equality of growth rates of both sides of $\left(4^{\prime}\right)$ requires

$$
\left(1+g_{c}\right)^{1-\sigma}=\left(\frac{1+g_{L}}{1+g_{N}}\right)^{1+\vartheta} \text { or } 1+g_{N}=\frac{1+g_{L}}{\left(1+g_{c}\right)^{1-\sigma / 1+\vartheta}}
$$

The comparable equation from the model solution is again linear in growth rates of $c$ and $L / N$.

$$
\left(1+g_{c}\right)=\left(\frac{1+g_{L}}{1+g_{N}}\right)\left(1+g_{h}\right)^{1+\frac{\epsilon}{\alpha}}
$$

Comparison of (6) and (7) as well as (4") and (8) show that the serendipity condition is not redundant and could determine the population growth rate.

\section{Calibration and Population Policy}

The relevance of the serendipity theorem stems from the current problem of ageing based on the fall of population growth in the second half of the 1960s. The question then is how far population levels and growth rates are away from the optimum. We extend the calibration in Gaessler [11] to calculate the optimal population growth rate from equation (4"). The calibration tries to get close to the average growth values for 14 OECD countries. The parameters for production function (1) and those in the household utility maximization are $\alpha=0.6$, $\delta_{h}=0.03, \quad g_{N}=0.002, \quad F=0.055, \gamma=0.268, \quad \epsilon=0.834, \quad \sigma=1.06$, $\beta=0.982, \vartheta=3$. The debt elasticity of the interest rate is a highly non-linear estimated function which depends on the debt/ratio itself [14]. Its values as well as those of the interest rate are part of the solution of the model. As indicated above the model can be reduced to a system in $e$ and $b$ depending on exogenous population growth rates. Table 1 shows results for alternative low population growth rates.

The last column of Table 1 shows that the population growth rate according to the serendipity condition in terms of growth rates are hard to distinguish from those put in by assumption in the first column. At these low levels of population growth there is essentially no incentive for population policies.

Table 1. Results for alternative low population growth rates.

\begin{tabular}{ccccccccccc}
\hline$g N$ & $g L$ & $g_{1+D}$ & $e$ & $b$ & $X$ & $1+r(1+\eta)$ & $1+g c$ & $1+g h$ & $\left(1+g_{Y}\right) /\left(1+g_{N}\right)$ & $1+g N o p t$ \\
\hline 0.003 & 0.00256 & 0.00044 & 0.3953 & 0.0473 & 0.688 & 0.0507 & 1.0298 & 1.0129 & 1.0306 & 1.003002 \\
0.002 & 0.00157 & 0.00043 & 0.3801 & 0.0383 & 0.694 & 0.0496 & 1.0287 & 1.0124 & 1.0295 & 1.001995 \\
0.001 & 0.00059 & 0.00041 & 0.3658 & 0.0297 & 0.700 & 0.0484 & 1.0277 & 1.0120 & 1.0285 & 1.001000 \\
0 & -0.0004 & 0.00040 & 0.3523 & 0.0216 & 0.706 & 0.0473 & 1.0267 & 1.0116 & 1.0275 & 0.999995 \\
-0.001 & -0.00138 & 0.00038 & 0.3396 & 0.0137 & 0.713 & 0.0463 & 1.0257 & 1.0112 & 1.0265 & 0.999000 \\
-0.002 & -0.00237 & 0.00037 & 0.3276 & 0.0062 & 0.720 & 0.0453 & 1.0248 & 1.0108 & 1.0256 & 0.997997 \\
-0.003 & -0.00327 & 0.00027 & 0.3213 & $-2 \mathrm{E}-05$ & 0.724 & 0.0444 & 1.0240 & 1.0106 & 1.0252 & 0.997085 \\
\hline
\end{tabular}


If the population gets older, this can perhaps be captured by a higher Frisch parameter if labour supply reacts more sluggishly to wage increases. Table 2 presents solutions of the model and for optimal population growth in the last column. Higher Frisch parameters imply higher optimal population growth rates between 0.0015 and 0.00225 when the model assumes a population growth rate of 0.002. Larger Frisch parameters therefore can be seen as an incentive for policies towards higher population growth. The most serious part of the problem of ageing may be the increase in the loss of human capital. In Table 3 we provide alternative solution of the model for different rates of human capital depreciation. Again, the deviations of the optimal population growth rate from equation (4") from unity in columns " $1+\mathrm{gN}$ opt" are hard to distinguish from rounding errors although the solutions of the growth rates of $c$ and $L$ depend on the whole model, which is first solved for $e$ and $b$, and from there goes into the interest and growth rates, and they all depend on the rate of human capital depreciation. The human capital loss of ageing does not increase the incentive for population growth policies.

The comparison of the theoretical model with the additional serendipity result (4), (4'), (4") and columns " $1+\mathrm{gN}$ opt" of Tables 1-3 show that conditions (4) (4") are not redundant and the choice of the population growth rates might lead to a better choice of growth paths. The result is interesting because all parts of the traditional golden rule are endogenous and optimized: the interest rate, the

Table 2. Model solutions for alternative Frisch parameters.

\begin{tabular}{ccccccccc}
\hline vartheta & $g N$ & $e$ & $b$ & $r$ & $\eta$ & $1+r(1+\eta)$ & $1+g h$ & $1+g L$ \\
\hline 1 & 0.002 & 0.3838 & 0.0423 & 0.0473 & 0.0586 & 1.0501 & 1.012551 & 1.001122 \\
2 & 0.002 & 0.3836 & 0.0447 & 0.0474 & 0.0615 & 1.0504 & 1.012545 & 1.001410 \\
3 & 0.002 & 0.3837 & 0.0459 & 0.0475 & 0.0630 & 1.0505 & 1.012547 & 1.001559 \\
4 & 0.002 & 0.3834 & 0.0466 & 0.0476 & 0.0639 & 1.0506 & 1.012539 & 1.001644 \\
5 & 0.002 & 0.3834 & 0.0471 & 0.0476 & 0.0644 & 1.0507 & 1.012538 & 1.001703 \\
6 & 0.002 & 0.3834 & 0.0475 & 0.0476 & 0.0649 & 1.0507 & 1.012537 & 1.001745 \\
7 & 0.002 & 0.3833 & 0.0477 & 0.0476 & 0.0652 & 1.0507 & 1.012536 & 1.001777 \\
8 & 0.002 & 0.3833 & 0.0479 & 0.0477 & 0.0654 & 1.0508 & 1.012536 & 1.001801 \\
\hline vartheta & $g N$ & $1+g Y$ & $X$ & $1+g c$ & $1+g W$ & $1+g(1+D)$ & $1+g Y / 1+g N$ & $1+g N o p t$ \\
\hline 1 & 0.002 & 1.03141 & 0.69250 & 1.02937 & 1.017488 & 1.00088 & 1.02936 & 1.0015567 \\
2 & 0.002 & 1.03170 & 0.69221 & 1.02965 & 1.017480 & 1.00059 & 1.02964 & 1.0018493 \\
3 & 0.002 & 1.03185 & 0.69201 & 1.02980 & 1.017483 & 1.00044 & 1.02979 & 1.002000 \\
4 & 0.002 & 1.03192 & 0.69198 & 1.02988 & 1.017472 & 1.00036 & 1.02986 & 1.0020862 \\
5 & 0.002 & 1.03198 & 0.69193 & 1.02993 & 1.017470 & 1.00030 & 1.02992 & 1.0021459 \\
6 & 0.002 & 1.03202 & 0.69189 & 1.02997 & 1.017469 & 1.00025 & 1.02996 & 1.0021887 \\
7 & 0.002 & 1.03205 & 0.69185 & 1.03000 & 1.017468 & 1.00022 & 1.02999 & 1.0022209 \\
8 & 0.002 & 1.03208 & 0.69183 & 1.03003 & 1.017467 & 1.00020 & 1.03002 & 1.002246 \\
\hline
\end{tabular}


Table 3. Model solutions for alternative rates of human capital depreciation.

\begin{tabular}{|c|c|c|c|c|c|c|c|c|}
\hline depr & $g N$ & $e$ & $b$ & $r$ & $\eta$ & $1+r(1+\eta)$ & $1+g h$ & $1+g L$ \\
\hline 0.01 & 0.002 & 0.341 & 0.540 & 0.074 & 0.347 & 1.09953 & 1.031 & 1.00091 \\
\hline 0.02 & 0.002 & 0.361 & 0.271 & 0.061 & 0.235 & 1.07482 & 1.022 & 1.00123 \\
\hline 0.03 & 0.002 & 0.384 & 0.046 & 0.048 & 0.063 & 1.05052 & 1.013 & 1.00156 \\
\hline 0.033 & 0.002 & 0.391 & -0.008 & 0.044 & -0.013 & 1.04331 & 1.010 & 1.00166 \\
\hline 0.034 & 0.002 & 0.393 & -0.025 & 0.043 & -0.042 & 1.04091 & 1.009 & 1.00169 \\
\hline 0.035 & 0.002 & 0.396 & -0.041 & 0.042 & -0.072 & 1.03852 & 1.008 & 1.00172 \\
\hline 0.036 & 0.002 & 0.398 & -0.057 & 0.040 & -0.105 & 1.03613 & 1.007 & 1.00175 \\
\hline 0.037 & 0.002 & 0.401 & -0.072 & 0.039 & -0.140 & 1.03375 & 1.006 & 1.00179 \\
\hline 0.038 & 0.002 & 0.403 & -0.086 & 0.038 & -0.177 & 1.03137 & 1.005 & 1.00182 \\
\hline 0.04 & 0.002 & 0.408 & -0.114 & 0.036 & -0.259 & 1.02662 & 1.003 & 1.00189 \\
\hline 0.05 & 0.002 & 0.435 & -0.228 & 0.026 & -0.878 & 1.00312 & 0.994 & 1.00221 \\
\hline 0.06 & 0.002 & 0.464 & -0.314 & 0.016 & -2.216 & 0.98003 & 0.985 & 1.00254 \\
\hline 0.07 & 0.002 & 0.495 & -0.383 & 0.008 & -6.371 & 0.95735 & 0.976 & 1.00288 \\
\hline depr & $g N$ & $1+g Y$ & $X$ & $1+g c$ & $1+g_{W}$ & $1+g(1+D)$ & $(1+g Y) /(1+g N)$ & $1+g N o p t$ \\
\hline 0.01 & 0.002 & 1.077 & 0.683 & 1.075 & 1.044 & 1.00109 & 1.075 & 1.0019999 \\
\hline 0.02 & 0.002 & 1.054 & 0.685 & 1.052 & 1.031 & 1.00076 & 1.052 & 1.0020002 \\
\hline 0.03 & 0.002 & 1.032 & 0.692 & 1.030 & 1.017 & 1.00044 & 1.030 & 1.0019999 \\
\hline 0.033 & 0.002 & 1.025 & 0.695 & 1.023 & 1.014 & 1.00034 & 1.023 & 1.0019999 \\
\hline 0.034 & 0.002 & 1.023 & 0.696 & 1.021 & 1.012 & 1.00031 & 1.021 & 1.0020001 \\
\hline 0.035 & 0.002 & 1.021 & 0.698 & 1.019 & 1.011 & 1.00028 & 1.019 & 1.0020000 \\
\hline 0.036 & 0.002 & 1.019 & 0.699 & 1.016 & 1.010 & 1.00025 & 1.016 & 1.0019999 \\
\hline 0.037 & 0.002 & 1.016 & 0.700 & 1.014 & 1.008 & 1.00021 & 1.014 & 1.0020001 \\
\hline 0.038 & 0.002 & 1.014 & 0.702 & 1.012 & 1.007 & 1.00018 & 1.012 & 1.0019999 \\
\hline 0.04 & 0.002 & 1.010 & 0.705 & 1.008 & 1.005 & 1.00011 & 1.008 & 1.0020000 \\
\hline 0.05 & 0.002 & 0.988 & 0.723 & 0.986 & 0.992 & 0.99979 & 0.986 & 1.0020001 \\
\hline 0.06 & 0.002 & 0.966 & 0.752 & 0.964 & 0.979 & 0.99946 & 0.964 & 1.0020002 \\
\hline 0.07 & 0.002 & 0.945 & 0.800 & 0.943 & 0.966 & 0.99913 & 0.943 & 1.0019997 \\
\hline
\end{tabular}

rate of technical change and labour supply growth. However, the deviation of the assumed from the optimal population growth rates are substantial only for variations of the Frisch elasticity, that is if ageing changes labour supply elasticities.

Equation (4) and its variations therefore broaden the serendipity results discussed in the introduction to the area of endogenous growth.

\section{Conclusion}

The serendipity theorem, suggesting that some rates of population growth may be better than others, turns out to be relevant in the third-best endogenous growth model with imperfect international capital movements as foreign debt, 
interest rates, labour supply growth and consumption paths are chosen optimally in the third best sense. We have considered the Benthamite case where the utility function is multiplied by the population size $N$. Other variants of utility functions could be analyzed in the same way.

\section{References}

[1] Samuelson, P.A. (1975) The Optimum Growth Rate for Population. International Economic Review, 16, 531-538. https://doi.org/10.2307/2525993

[2] Diamond, P. (1965) National Debt in a Neoclassical Growth Model. American Economic Review, 55, 1126-1150.

[3] Deardorff, A.V. (1976) The Growth Rate for Population: Comment. International Economic Review, 17, 510-515. https://doi.org/10.2307/2525720

[4] Michel, Ph. and Pestieau, P. (1993) Population Growth and Optimality: When Does Serendipity Hold? Journal of Population Economics, 6, 353-362. https://doi.org/10.1007/BF00599043

[5] Abio, G. (2003) Interiority of the Optimal Population Growth Rate with Endogenous Fertility. Economic Bulletin, 10, 1-7.

[6] Jaeger, K. and Kuhle, W. (2009) The Optimum Growth Rate for Population Reconsidered. Journal of Population Economics, 22, 23-41. https://doi.org/10.1007/s00148-007-0184-1

[7] De la Croix, D., Pestieau, P. and Ponthière, G. (2012) How Powerful Is Demography? The Serendipity Theorem Revisited. Journal of Population Economics, 25, 899-922. https://doi.org/10.1007/s00148-011-0362-z

[8] Felder, S. (2016) How Powerful Is Demography? The Serendipity Theorem revisIted. Comment on De la Croix et al. (2012). Journal of Population Economics, 29, 957-967. https://doi.org/10.1007/s00148-016-0587-y

[9] Boucekkine, R., Martínez, B. and Ruiz-Tamarit, J.R. (2017) Optimal Population Growth as an Endogenous Discounting Problem: The Ramsey Case. HAL Id: halshs-01579155.

[10] Lucas Jr., R.E. (1988) On the Mechanics of Economic Development. Journal of Monetary Economics, 22, 3-42. https://doi.org/10.1016/0304-3932(88)90168-7

[11] von Gaessler, A.E. and Ziesemer, T. (2017) Ageing, Human Capital and Demographic Dividends with Endogenous Growth, Labour Supply and Foreign Capital, UNU-MERIT WP 2017-043.

[12] Dedry, A., Onder, H. and Pestieau, P. (2016) Aging, Social Security Design, and Capital Accumulation. The Journal of the Economics of Ageing, 145-155.

[13] Muysken, J. and Ziesemer, T.H.W. (2014) The Effect of Immigration on Economic Growth in an Ageing Economy. Bulletin of Applied Economics, 1, 37-65. http://www.riskmarket.co.uk/bae/journals-articles/issues/1_1_3/?download=attach $\underline{\text { ment.pdf }}$

[14] von Gaessler, A.E. and Ziesemer, T. (2016) Optimal Education in Times of Ageing: The Dependency Ratio in the Uzawa-Lucas Growth Model. The Journal of the Economics of Ageing, 7, 127-142. https://doi.org/10.1016/j.jeoa.2016.03.001 